\title{
A STRAIGHT FORWARD, FAST, SENSITIVE, EPI- HPLC- MS/MS METHOD FOR THE SIMULTANEOUS ESTIMATION OF CLOZAPINE AND AMITRIPTYLINE IN HUMAN PLASMA
}

\author{
Muni Krishnaiah $A^{1}$, C. Rama Chandraiah ${ }^{1, *}$, M. Srinivas ${ }^{2}$ and N. Devanna ${ }^{3}$ \\ ${ }^{1}$ Research Scholar, Department of Chemistry, JNTUA, Anantapur, Andhra Pradesh, India. \\ ${ }^{1}$ Department of Chemistry, Sri Kalahastheeswara Institute of Technology, \\ Srikalahasthi, Andhra Pradesh, India. \\ ${ }^{2}$ Acubiosys Pvt. Ltd., Technology Business incubator, BITS Pilani Campus, \\ Jawaharnagar, Hyderabad, India. \\ ${ }^{3}$ Department of Chemistry, College of Engineering, JNTUA, Anantapur, Andhra Pradesh, India. \\ *E-mail: cramachandraiah@yahoo.com
}

\begin{abstract}
For the simultaneous detection and accurate results of Clozapine and Amitriptyline in a human plasma, a very penetrative and plain High-Performance Liquid Chromatographic- tandem Mass spectrometry was used. To pull out the analyte and IS from human plasma Precipitation method was utilized. By using gradient flow of $\mathrm{C} 18$ column the chromatographic resolution of Clozapine, Amitriptyline and corresponding IS was achieved. The whole chromatographic runtime was $3 \mathrm{~min}$. For clozapine and Amitriptyline the range of concentration is $1-1000 \mathrm{ng} / \mathrm{mL}$ was used to obtain linear response function. As per the regulatory guidelines the intra-day and inter-day accuracy and precision values were obtained for Clozapine and Amitriptyline.
\end{abstract}

Keywords: Amitriptyline, Clozapine, LC-MS/MS, Simultaneous Estimation, Gradient Technique.

(C) RASĀYAN. All rights reserved

\section{INTRODUCTION}

A tricyclic dibenzoazepine (Clozapine), named an ordinary antipsychotic agent. ${ }^{1}$ It ties various kinds of focal sensory system receptors, and presentations an unmistakable pharmacological profile. Clozapine is a serotonin foe, with solid authoritative to 5 -HT $2 \mathrm{~A} / 2 \mathrm{C}$ receptor subtype. It additionally shows a wellconstructed likeness to some dopaminergic receptors, yet demonstrates just delicate hostility at the dopamine D2 receptor, a receptor, for the most part, thought to regulate neuroleptic movement.Clozapine is a psychotropic specialist having a place with the concoction class of benzisoxazole subordinates and is demonstrated for the healing of schizophrenia. Clozapine is a particular monoaminergic enemy with elevated proclivity for the serotonin Type 2 (5HT2), dopamine Type 2 (D2), 1 and 2 adrenergic, and H1 histaminergic receptors. However with mediocre adequacy, to previous receptors Clozapine acts as an opponent. Threats at receptors but dopamine and 5HT2 with closely resembling receptor affinities may portray a portion of the more helpful and reactions of Clozapine. The Clozapine risk of muscarinic M1-5 receptors may clarify its anticholinergic impacts. Clozapine hostility of histamine H1 receptors may clarify that the sluggishness saw with this medication. Clozapine opposition of adrenergic a1 receptors may clarify the orthostatic hypotension ${ }^{2}$ saw with this prescription.

Amitriptyline hydrochloride is a dibenzocycloheptene-derivative tricyclic antidepressant ${ }^{3}$ (TCA) and analgesic. Phenothiazine's and TCAs are analogous with each other, and alkyl amine substituent on the central ring forms a tricyclic ring system. It does not change mood or arousal in non-depressed individuals but can cause sedation. The positive effect is exerted by amitriptyline in depressed individuals. For serotonin and norepinephrine reuptake TCAs acts as intense inhibitors. TheTCAs downcontrol similarly intellectual cortical $\beta$-adrenergic receptors and whet post-synaptic serotonergic receptors with ceaseless exploit. In general, enhance in serotonergic neurotransmission is considered to be anti-

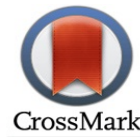


RASĀYAN J. Chem.

Vol. 13 | No. 1 |24 - 37| January - March | 2020

depressant thing of TCAs. TCAs blocked the Histamine- $\mathrm{H}_{1}$ receptors, $\alpha_{1}$-adrenergic receptors and muscarinic receptors which narration for the hypotensive and anticholinergic possessions correspondingly. In the healing of sadness, diabetic neuropathy, post-traumatic stress disorder, Amitriptyline may be used. Amitriptyline is a $3^{\circ}$ amine tricyclic anti-depressant that is chemically associated mutually with cyclobenzaprine and thiothixene. It provides excessive progress in the action of sleep patterns. Amitriptyline exhibits physically powerful anticholinergic action, cardiovascular effects ${ }^{4}$. To understand the clinical gain a number of weeks of therapy are required. Amitriptyline is extensively worn in the running of chronic nonmalignant pain.

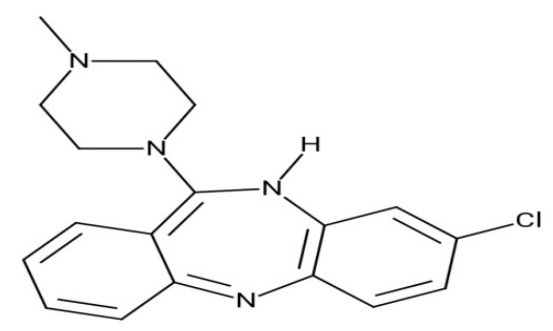

Fig.-1:(a)Structural representation of Clozapine<smiles>CN(C)CCC=C1c2ccccc2CCc2ccccc21</smiles>

Fig.-1:(b)Structural representation of Amitriptyline

A combination of antipsychotics drug therapy is used to treat schizophrenia or mania which is the most interesting topic in generic pharmaceutical industry, hence author believes that the simulations estimation method of these drugs in plasma samples would supply significantly to pharmaceutical industry. In literature survey for estimation of Clozapine in plasma, several methods were proposed, such as Capillary electrophoresis, ${ }^{5-8} \mathrm{HPLC}^{9-14} \mathrm{GC}-\mathrm{MS}^{15,16}$ and LC-MS. ${ }^{17-19}$ For estimation of Amitriptyline in plasma several methods were proposed, such as Capillary electrophoresis, ${ }^{20-22} \mathrm{GC}^{23-24} \mathrm{HPLC}^{25,}{ }^{26}$, RP-HPLC ${ }^{27,28}$ and by LC-MS. ${ }^{29-32}$ As far as there is no simultaneous UPLC-MS/MS strategy for assessment of Clozapine and Amitriptyline in human plasma tests for estimating Clozapine plasma concentrations, particularly in the later period of disposal, a very delicate assay is required that is influenced by neither plasma segments nor different medications given at the same time.

Our current effort relates a straightforward, novel, fast, reactive to and choosy process for instantaneous determination of Clozapine and Amitriptyline by advanced UPLC-MS/MS equipment. The current method offers many advantages i.e. shorter runtime, less sample volume and can estimate both compounds in a single run. In the current method, Clozapine and Amitriptyline were used as internal standards, the compound composition of Clozapine is shown in Fig.-1 (a) and Amitriptyline in Fig.-1 (b). This technique can be useful to pharmacokinetic study of plasma Clozapine and Amitriptyline concentration after oral administration.

\section{Chemicals and Reagents}

\section{EXPERIMENTAL}

Clozapine and Amitriptyline are obtained from Merck private limited, Bangalore. HPLC grade Acetonitrile (100\%), Ammonium acetate and Water utilized as a part of the whole study was set up from Milli-Q water purifier framework obtained from Millipore. Clear human plasma was acquired from 
RASĀYAN J. Chem.

Vol. 13 | No. 1 |24 - 37| January - March | 2020

Supratech Micropath. Ammonium acetic acid utilized for the portable stage groundwork is of GR review and acquired from Merck.

\section{LC-MS/MS Instrumentation and Chromatographic Methods}

The instrument was operated in the positive mode which is outfitted with an electrospray particle utilizing nitrogen as the collision, curtain gas, nebulizer and auxiliary and is comprised of HPLC attached to AB Sciex API-4000 mass spectrometer. The HPLC framework comprised of two LC20AD drives, online DGU-20A3 dissolvable degasser, a SIL-HTc autosampler, and a CTO20A segment broiler. The highperformance liquid chromatography section was a C18-XBridge segment $(4.6 \times 50 \mathrm{~mm}, 3.5 \mu \mathrm{m}) \mathrm{kept}$ up at $400 \mathrm{C}$ with a stream rate of $1.0 \mathrm{~mL} / \mathrm{min}$ with the split proportion of $60: 40$. The versatile stage comprised of $0.1 \%$ formic corrosive (An) and Acetonitrile (B). The primary versatile stage organization was $95 \%$ $\mathrm{A} / 5 \% \mathrm{~B}$ and proceeded until $0.8 \mathrm{~min}$, at that point it was changed to $5 \% \mathrm{~A} / 95 \% \mathrm{~B}$ more than 2.2 minutes. After $2.2 \mathrm{~min}$, the versatile stage is gradually moved to $95 \% \mathrm{~A} / 5 \%$ B by 2.4 min following which it was held at same for 3.5 minutes. The chromatograms were obtained utilizing expert programming (rendition 1.4.1, Applied Bio frameworks, Ontario, Canada). Clozapine and Amitriptyline standardization curves were fabricated by applying the weighted least squares method to the analyte of internal standard versus concentration.

\section{Preparation of Samples Stock Solutions, Standardisation, and Quality Control}

In Acetonitrile inside measures and stock arrangements of the analyte was set up in the range 1 to $10^{\circ} \mathrm{C}$. According to the recognition of chemical analysis the fixations of purity, real weighted sum, and wetness content were adjusted. To measure the standardization curve and quality control (QC) samples working arrangements of Acetonitrile: water $(50: 50 \mathrm{v} / \mathrm{v})$ was set up independently. To accomplish the attractive grouping of each analyte the $1 \%$ spiking of these working arrangements was done exclusively in plasma. Every calibration curve comprised of one clear example prepared with IS, and eight calibration points focus running from 1.0- $1000 \mathrm{ng} / \mathrm{mL}$ for Clozapine and Amitriptyline. The QC samples spiked freely of the CC standard stock included the limit of quantification quality control (LOQQC), low-quality control (LQC), middle-quality control (MQC), and high-quality control (HQC). Aliquots of the CC and QC principles were put away beneath $-50^{\circ} \mathrm{C}$.

\section{Method Validation}

\section{Mobile Phase Optimization}

To increase LC division and identification sensitivity for the LC-MS technique versatile stages and LC slopes were highly developed. Acetonitrile is utilized as washing out substance for detachment since advanced $\pi-\pi$ contact among the aromatic rings, yet indicated reduced elution property. Alternatively formic acid indicated poor determination, in light of the fact that analyte needs impartial or essential $\mathrm{pH}$, thus ammonium acetic acid derivation is added to fluid stage to hold for quite a while.

\section{Internal Standard Selection}

To begin with, Metoprolol was utilized as IS for positive mode compounds. Metoprolol needs acidic PH for elution however Clozapine and Amitriptyline need impartial PH and weakening with water for supernatant which gets after extraction. Henceforth was settled at long last for positive mode, which demonstrated great elution and resolution property.

\section{Recovery}

The recovery is associated with the capability of the descriptive separation strategy, inside variability levels. The recovery of an analyte ought not to be $100 \%$; in any case, the measure of analyte recovered and of the internal standard must be predictable, correct and recoverable. The extraction effectiveness of analyte and IS human plasma was settled from iterative QC samples $(n=6)$ responses were spiked in post expelled human plasma clear case at proportionate fixation. Single concentration was used to choose recovery of IS however in case of analyte (Clozapine and Amitriptyline) the recovery was settled at LQC and furthermore HQC fixations. 
RASĀYAN J. Chem.

Vol. 13 | No. 1 |24 - 37| January - March | 2020

\section{Carryover}

Inside each group, the particular example exclusive of the inner pattern is infused promptly later than the most utmost pattern to check that carryover is fewer than $20 \%$ of the LLOQ on a peak region pattern.

\section{Selection of HPLC Column}

To start with, turned around stage C-8 and C18, X-connect segments were utilized as an HPLC section for this objective analyte. Different elements together with the piece of the versatile stage and levels ofpH were additionally analyzed; be that as it may, no critical enhancement in the chromatographic partition was acquired essentially because of their comparable physicochemical properties. Because of extremity and fragrant selectivity kinetex EVO C18 $(5 \mathrm{u}, 50 * 4.6 \mathrm{~mm})$ exhibits great goals, symmetrical pinnacles and less co-elution between target mixes. According to LC-MS strategy enhance LC partition and recognition affectability connection of versatile stages and LC slopes were advanced. Acetonitrile was used as eluent for separation.

\section{Calibration Curve}

Five recurrent arrangements of quantitation models were used to discover the linearity of response, each set orchestrated on substitute day anyway using comparative plasma and weaken stock arrangement were readied, apiece having 9 different center stages (alignment gauges of analyte) in human plasma. This will be alluded to as entomb and intra-day information and will indicate that the measure is solid and reproducible on different days. The most negligible level was assessed and estimated by LC-MS/MS at the point of examination.

From the isolated molecule chromatogram, the pinnacle region for each analyte was settled and parceled by the pinnacle territory of the inside standard gained comparatively. This was plotted against the ostensible centralization of analyte. The least difficult reasonable type of relapse was selected as essentially the FDA. For this circumstance it was immediate $1 / \mathrm{x}$ or $1 / \mathrm{x} 2$ where $\mathrm{x}$ was the fixation. This gave the alignment bend a more grounded weighting to near the lower end of the change twist.

\section{Specificity and Selectivity}

Specificity is a technique that delivers a reaction for just a single analyte. Selectivity is the capacity of an approach to deliver a reaction for the objective analyte recognizing it from every other obstruction. The primary concern is the reaction of the LLOQ norms ought to be more than the reaction from the blank biological matrix by a defined factor. The selectivity of the technique was surveyed utilizing eight distinct loads of human K3EDTA plasma by viewing for the reactions of the noseyconstituents at the retention times of the analyte and internal standards. Obstruction in each plasma assemble was contrasted and six (LOQ) tests, orchestrated by assembling two customary clear lattice clumps with immaterial or no pinnacle zone reaction at the maintenance time everything being equal. Response of the meddling tops at the maintenance times of the analyte and inside standard in the clear framework must be $\leq 20 \%$ of the mean pinnacle zone response of the analyte in the LOQ tests for the analyte and must be $\leq 5 \%$ of the mean pinnacle territory response of the inner standard in the LOQ tests for ISTD. The peaks to-noise extent of each LOQ test should be no under five times of that of the clear framework tests. To display the linearity of the procedure four adjustment bends were used. The best-fit curves by means of weighted linear least square regression examination were attained by the pinnacle zone extent of the analyte to inside standard versus analyte fixation. A relationship coefficient $r>0.99$ was appealing for all the adjustment bends.

\section{Exactness and Accuracy}

The exactness chooses the closeness of agreement between movements of estimations from various analyzing of the same homogenous test under suggested condition. The coefficient of variance should not run past $15 \%$ except for the LLOQ, where it should not surpass $20 \%$. The accuracy of an analytical technique communicates the proximity of contract among predictably correct value or an accepted reference value. The strategy of intra-and inter-day exactness and accuracy was resolved in the analysis of human K3EDTA plasma. They were assessed by reproducing the study of exactness and accuracy (PA) batches. Each level comprised of CC measures and six duplicates of QC at every PA batch. At the same time two PA batches handled to obtain intraday exactness and accuracy. Inter day test exactness and 
RASĀYAN J. Chem.

Vol. 13 | No. 1 |24 - 37| January - March | 2020

accuracy were controlled by breaking down PA batches carry on in the term of 3 days. The analyte signal of the LOQ/LOQQC test ought to be particular, distinct, and recoverable with precision $(\% \mathrm{CV})$ not more than $20.0 \%$ and accuracy within $20.0 \%$. For values/QC samples other than the LOQ/LOQQC, accuracy ought to be inside $15 \%$ and precision should be below 15 .

\section{Matrix Effect}

The exactness and sensitivity of the strategy were not traded off in the analysis of the Matrix effect. Keeping into mind the end goal to appraise, lipemic and hemolyzed were involved in six lots of plasma matrix and the LOQQC and HQC concentration levels were spiked in replica. Likewise, six LOQQC and HQC samples and newly spiked CC values were put together in plasma and operated. The newly spiked $\mathrm{CC}$ measures are calculated against the QC samples. Working arrangements of the drug and ISTD of QC samples were at $100 \%$ extraction at low, center and high concentrations to figure out Absolute Matrix Effect characteristics. From the screened blank matrix, six aliquots from every one of six varied batches are taken which includes one lipemic and one hemolyzed matrix and are prepared without the expansion of interior standard. At each level the last extracted concentration of the analyte is reassembled with the post extracted blank matrix of two aliquots. At each QC level \%CV should be less than or equal to $15 \%$ indicates that the AME is valuable. AME is defined as the ratio of mean signal area response in existence of matrix ions to the Mean peak area response without matrix ions when $A M E=1$ shows that there is no matrix effect, AME 1 demonstrates the improvement in ion. Recovery was created by looking at the mean peak area of the analyte the extraction strategy was controlled by plasma samples which are pre-spiked at LQC,MQC and HQC levels represents 100\% removal of the QC samples. Alternatively, $100 \%$ extraction of ISTD sample is possible with the dilution of MQC samples.

\section{Stability Experiments}

To demonstrate the concentration of analyte between the periods of assessment to the time of sampling stability assessment is taken into account. The stability of the analyte is enhanced in a very short period.

At each level for LQC and HQC samples, six replicates were utilized for the accompanying stability parameters:

1. Freeze-Thaw stability finished for three cycles

2. Auto-sampler stability

3. Benchtop stability

Under various conditions in plasma, the stability of the analyte was assessed along with the test dealing and analyzed by Method validation. By looking at the area response of the analyte and internal standard, stock solution stability was performed. By matching the peak area response of solution which is kept in ice-cold water below small light with the newly arranged solution, stability of each analyte is assessed. By keeping the human plasma in ice-cold water under low light for $\sim 7 \mathrm{~h}$ stability was determined. Similarly QC samples were kept under $\left(10^{\circ} \mathrm{C}\right)$ autosampler conditions for $\sim 72 \mathrm{~h}$ to determine the autosampler stability. The samples that had frozen at $-50^{\circ} \mathrm{C}$ and deforested 3 times at $25^{\circ} \mathrm{C}$ gives the freeze-thaw stability. At each level of LQC and HQC four replicates were utilized for stability studies. The steadystate of the analyte was obtained if \% change was under 15. New human K3EDTA plasma was kept in cold water shower for $\sim 2.5 \mathrm{~h}$ for sample accumulation and stability. Fresh blood was spiked again after the stability period and these samples are filled with examination samples which should be centrifuged at $4^{\circ} \mathrm{C}$. The subsequent plasma was gathered and handled according to the development of analytical method. By infusing all QC samples from and acknowledged precision-accuracy batch re-injection reproducibility was obtained. The CC samples were resolved against QC samples for the same batch was analyzed for $48 \mathrm{~h}$ previously. The difference in percentage between re-injected and original sample was intended by utilizing equation: \%Difference=Original value-re-injected value original value X100. By injecting the copies of upper limit of quantification ULOQ and LOQ with blank processed sample the carryover in the matrix was analyzed. By relating the zone response of Iblank matrix to the IIblank matrix in contradiction of mean peak zone of the analyte and ISTD, the interferences in retention time and ISTD were assessed. The sample whose concentration is two times $90 \%$ of the ULOQ was used to perform dilution integrity 
RASĀYAN J. Chem.

Vol. 13 | No. 1 |24 - 37| January - March | 2020

test. To bring the concentration these samples were diluted with blank matrix up to two to four times and then analyzed with fresh CC samples.

\section{RESULTS AND DISCUSSION}

Optimization of MS Parameters and Chromatographic Conditions

API 4000 triple quadrupole instrument was used by the recognition of the Mass Spectrometry. The apparatus was functioned in positive ion and outfitted with an ESI source. To obtain the lower LOQ increase the signal to noise ratio of the analyte. During the enhancement of internal standard and ion transitions $(\mathrm{m} / \mathrm{z})$ were noted as $326.9 \rightarrow 192.2,278.1 \rightarrow 178.3$ were chosen for the MRM of Clozapine and Amitriptyline separately (Fig.- 2a \& b and Fig.-3a \& b).

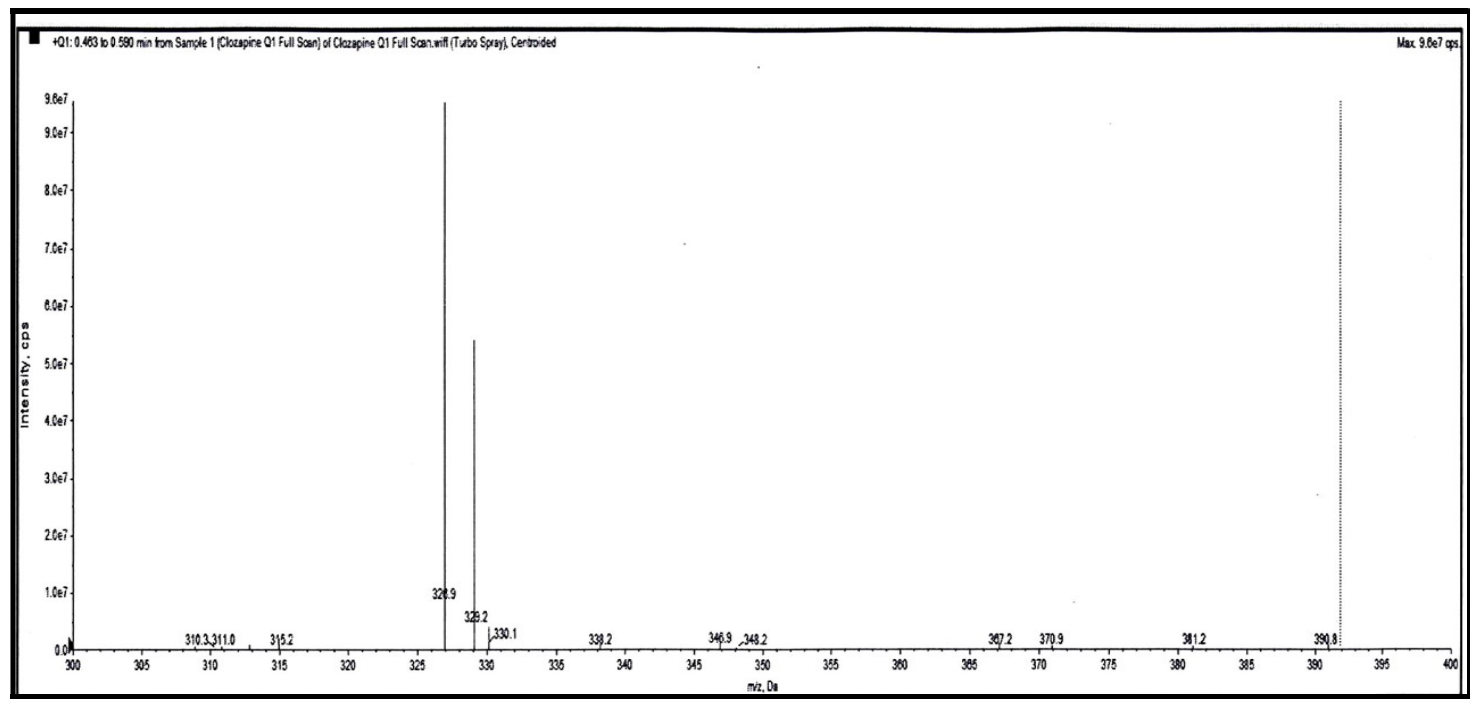

Fig.- 2:(a) Q1 MS Scan Window shows Abundant Parent ion at $\mathrm{m} / \mathrm{z}$ of Clozapine.

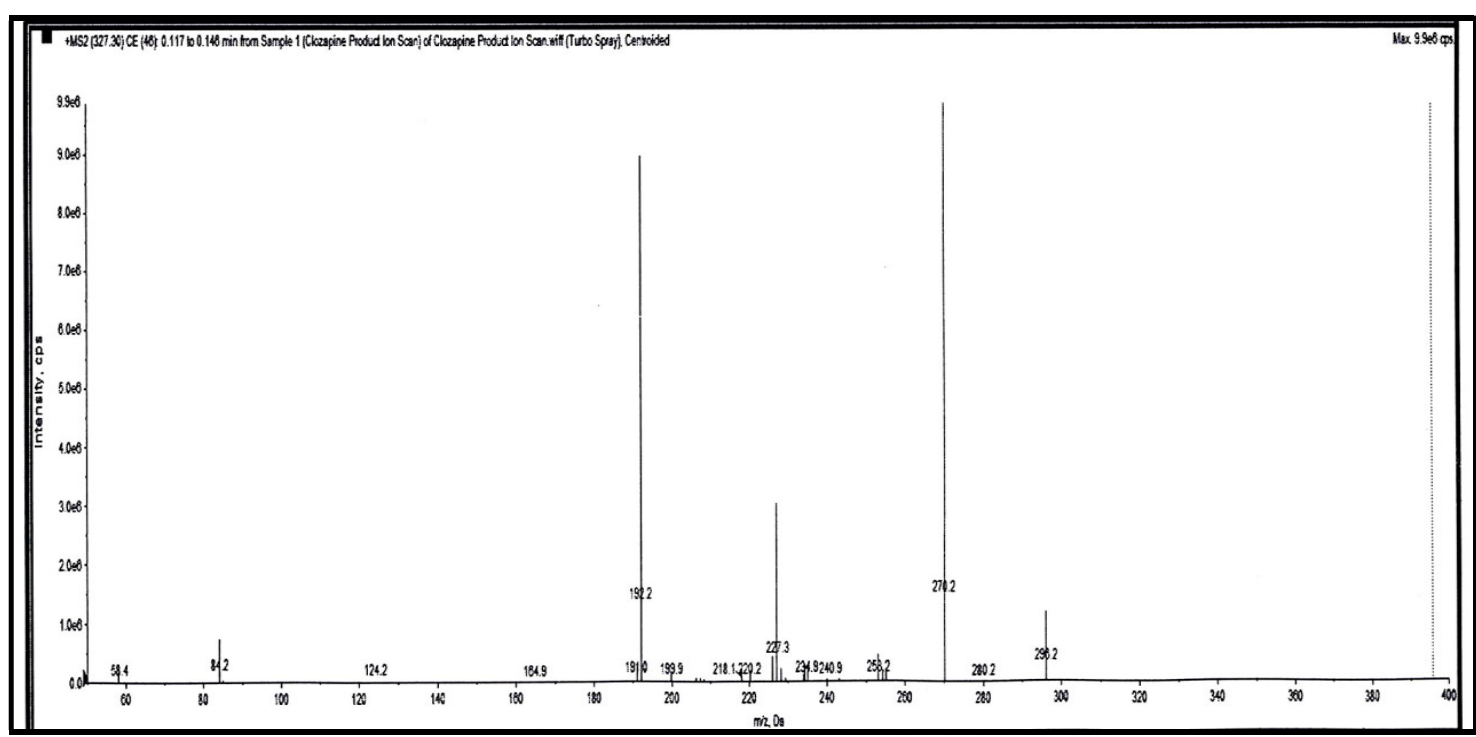

Fig.-2: (b) Mass Spectra of Product of Clozapine in Positive Ion Mode.

Each analyte is infused by a syringe pump for the optimization of the source and compound parameters were finished. The compound specifications were upgraded as declustering potential: 70 and $80 \mathrm{~V}$, starting potential: $10 \mathrm{~V}$, collision cell exit potential: 14 and $24 \mathrm{~V}$ and collision energy: 39 and $24 \mathrm{~V}$ for Clozapine and Amitriptyline separately. The source/gas specifications were enhanced as curtain gas: 30 , blow gas: 8 , ion source gas-1: 50 , ion source gas-2: 50 , ion spray voltage: $5500 \mathrm{~V}$ and temperature: $550^{\circ} \mathrm{C}$. The 
RASĀYAN J. Chem.

Vol. 13 | No. 1 |24 - 37| January - March | 2020

production scans of Clozapine and Amitriptyline have appeared in Table-1. Essential specifications like $\mathrm{pH}$ of the versatile stage, concentration and type of the buffer (ammonium acetic acid and $\mathrm{NH}_{4} \mathrm{HCO}_{2}$ ) solution $\%$ and kind of the organic modifier $\left(\mathrm{CH}_{3} \mathrm{CN}\right.$ and $\left.\mathrm{MeOH}\right)$, diverse sections (reverse phase columns for example, Discovery C18, Synergie MAX RP, Kinetix EVOC18, and Phenomenex Luna), and distinctive stream rates $(0.4-1.8 \mathrm{~mL} / \mathrm{min})$ were endeavoured for better sensitivity and better chromatographic division of Clozapine and Amitriptyline. The partition was observed to be influenced by expanding the molarity of the $\mathrm{NH}_{4} \mathrm{HCO}_{2}$ buffer and observed to be better with methanol when contrasted with Acetonitrile. Trials have demonstrated that the portable stage, acetonitrile: $5 \mathrm{mMNH}_{4} \mathrm{HCO}_{2}$ support at a stream rate of $1 \mathrm{~mL} / \mathrm{min}$, with the Kinetix EVOC18 segment invalidated the issues without bargaining on the affectability, range, and accuracy of the technique.

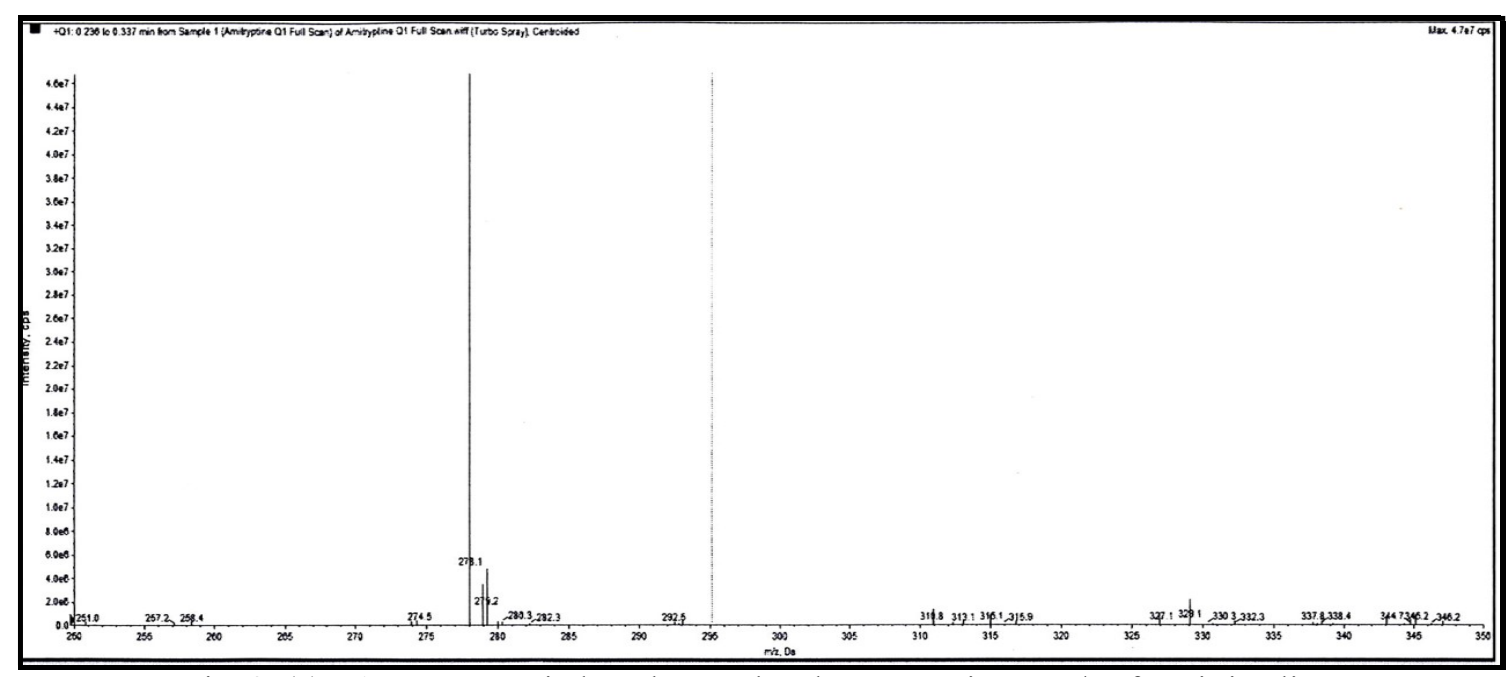

Fig.-3: (a) Q1 MS Scan Window shows Abundant Parent ion at m/z of Amitriptyline.

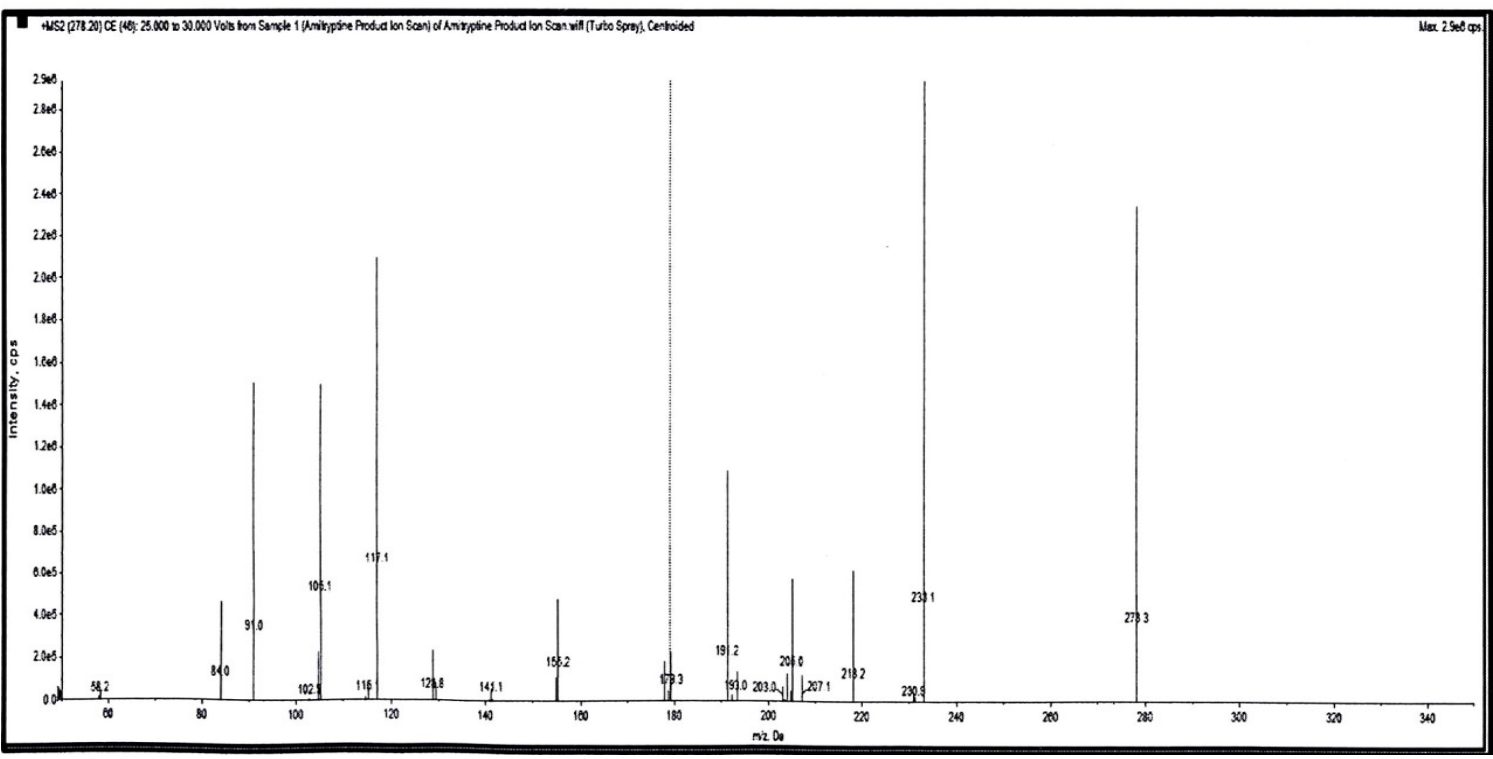

Fig.-3: (b) Mass Spectra of Product of Amitriptyline in Positive Ion Mode Table-1: Summary of MRM Transitions

\begin{tabular}{c|c|c|c|c|c|c|c}
\hline Compound & $\begin{array}{c}\text { Mode of } \\
\text { Ionization }\end{array}$ & $\mathrm{Q}_{1}$ mass $(\mathrm{m} / \mathrm{z})$ & $\begin{array}{c}\mathrm{Q}_{3} \text { mass } \\
(\mathrm{m} / \mathrm{z})\end{array}$ & $\mathrm{DP}$ & $\mathrm{EP}$ & $\mathrm{CE}$ & $\mathrm{CXP}$ \\
\hline Clozapine & Positive & 326.9 & 270.2 & 56 & 15 & 30 & 3 \\
\hline Amitriptyline & Positive & 277.4 & 233.1 & 36 & 11 & 27 & 4 \\
\hline
\end{tabular}


RASĀYAN J. Chem.

Vol. 13 | No. 1 |24 - 37| January - March | 2020

\section{Linearity}

By using the Analyst 1.5 programming and 1x linear regression method calibration curve was obtained. The back figured intra-batch information for standard curves is introduced in Table-2 and Table-3. Standard with a back-calculated accuracy outside the scope of $85-115 \%$ of the superficial concentration was expelled from the regression statistics. All calibration curves had the correlation coefficients more than 0.99 .

Table-2: Back Calculated Standard Curve Data for Clozapine in Human Plasma

\begin{tabular}{l|l|l|l|l|l|l|l}
\hline \multicolumn{9}{l}{ Concentration(ng/ml) } \\
\hline Std. Conc. & Batch 1 & Batch 2 & Batch 3 & Mean & SD & $\%$ CV & \% Accuracy \\
& & & & & & & \\
\hline 1 & 0.92 & 0.94 & 1.02 & 0.96 & 0.05 & 5.51 & 96.00 \\
\hline 2 & 2.31 & 2.23 & 2.36 & 2.30 & 0.07 & 2.85 & 115.0 \\
\hline 10 & 9.98 & 9.87 & 9.9 & 9.92 & 0.06 & 0.57 & 99.17 \\
\hline 50 & 57.17 & 56.24 & 55.31 & 56.24 & 0.93 & 1.65 & 112.48 \\
\hline 200 & 221.1 & 223.8 & 219.34 & 221.45 & 2.28 & 1.03 & 110.73 \\
\hline 500 & 461.1 & 453.51 & 451.43 & 455.35 & 5.09 & 1.12 & 91.07 \\
\hline 800 & 714.76 & 752.22 & 756.34 & 741.11 & 22.91 & 3.09 & 92.64 \\
\hline 900 & 823.13 & 820.33 & 818.54 & 820.67 & 2.31 & 0.28 & 91.19 \\
\hline 1000 & 971.3 & 955.16 & 934.27 & 953.58 & 18.57 & 1.95 & 95.36 \\
\hline
\end{tabular}

\section{Exactness and Precision}

Intra-batch ( $\mathrm{n}=6 /$ batch, 3 days) and inter-batch $(\mathrm{n}=18)$ accuracy and precision for Clozapine and Amitriptyline in Table-4. The outcomes demonstrate valuable accuracies, particularly when considering the multistep sample test preparation methodology, mainly among $90-110 \%$ of the insignificant concentrations. The respective chromatogram of blank, LLOQ, ULOQ chromatograms of Clozapine and Amitriptyline are represented from Fig.-4-9. The coefficients of variety for each analyte, mutually intraand inter-day, are likewise fine beneath the supposed criterion of fewer than $15 \%$.

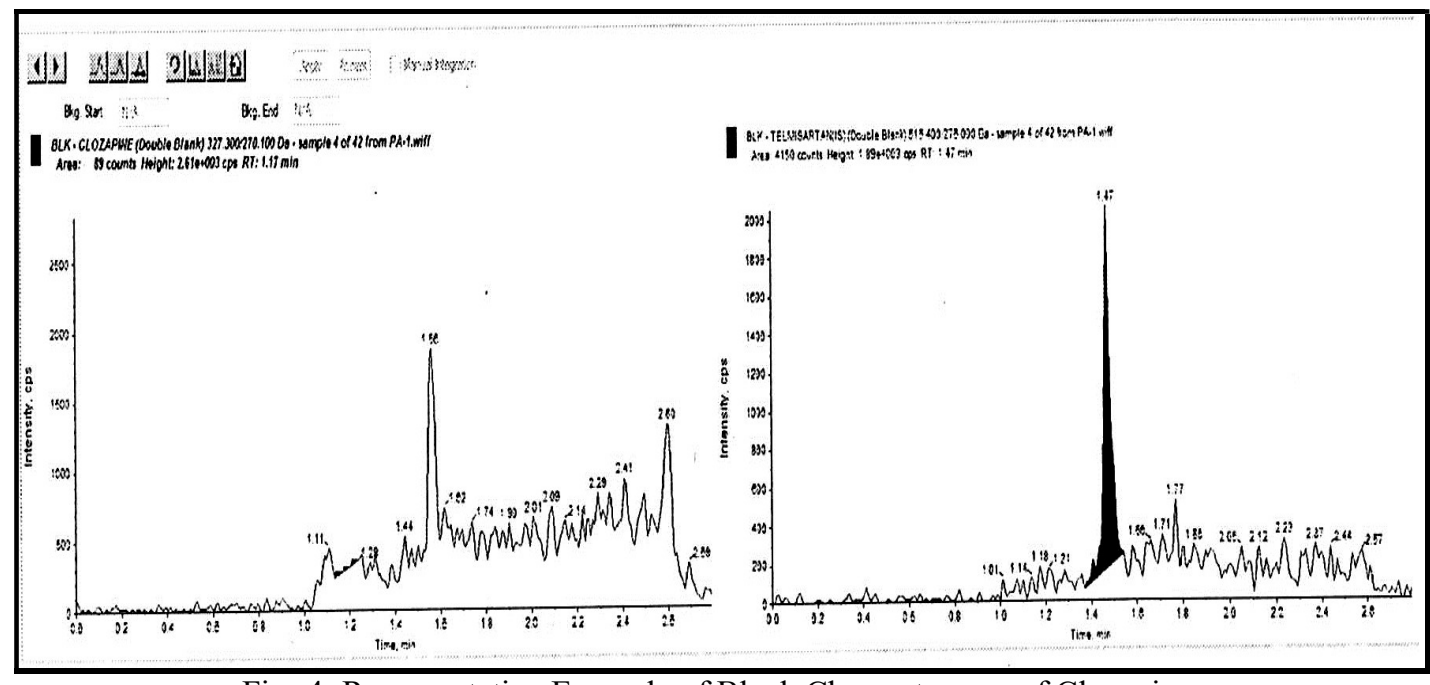

Fig.-4: Representative Example of Blank Chromatogram of Clozapine.

Table-3: Back Calculated Standard Curve Data for Amitriptyline in Human Plasma

\begin{tabular}{c|c|c|c|c|c|c|c}
\hline \multicolumn{7}{c}{ Concentration(ng/ml) } \\
\hline Std. Conc. & Batch 1 & Batch 2 & Batch 3 & Mean & SD & $\%$ CV & \% Accuracy \\
\hline 1 & 1.05 & 0.98 & 0.97 & 1.00 & 0.04 & 4.36 & 100 \\
\hline 2 & 2.18 & 2.51 & 2.08 & 2.26 & 0.23 & 9.97 & 112.83 \\
\hline 10 & 11.03 & 10.85 & 10.14 & 10.67 & 0.47 & 4.41 & 106.73 \\
\hline
\end{tabular}

31 
RASĀYAN J. Chem.

Vol. 13 | No. 1 |24 - 37| January - March | 2020

\begin{tabular}{c|c|c|c|c|c|c|c}
\hline 50 & 52.25 & 58.48 & 55.43 & 55.39 & 3.12 & 5.62 & 110.77 \\
\hline 200 & 212.25 & 225.45 & 219.34 & 219.01 & 6.61 & 3.02 & 109.51 \\
\hline 500 & 445.53 & 442.64 & 439.21 & 442.46 & 3.16 & 0.72 & 88.49 \\
\hline 800 & 775.8 & 766.73 & 768.12 & 770.22 & 4.89 & 0.63 & 96.28 \\
\hline 900 & 852.24 & 848.16 & 853.12 & 851.17 & 2.65 & 0.31 & 94.57 \\
\hline 1000 & 1059.85 & 1047.91 & 1021.07 & 1042.94 & 19.8 & 1.90 & 104.29 \\
\hline
\end{tabular}

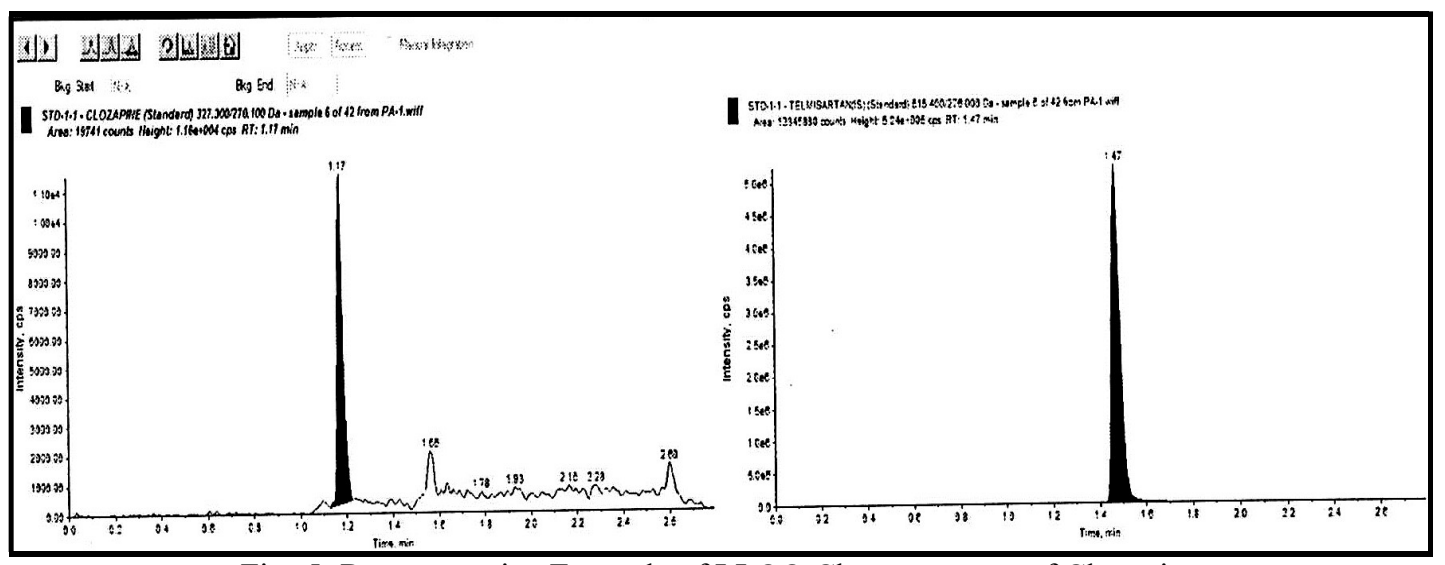

Fig.-5: Representative Example of LLOQ Chromatogram of Clozapine

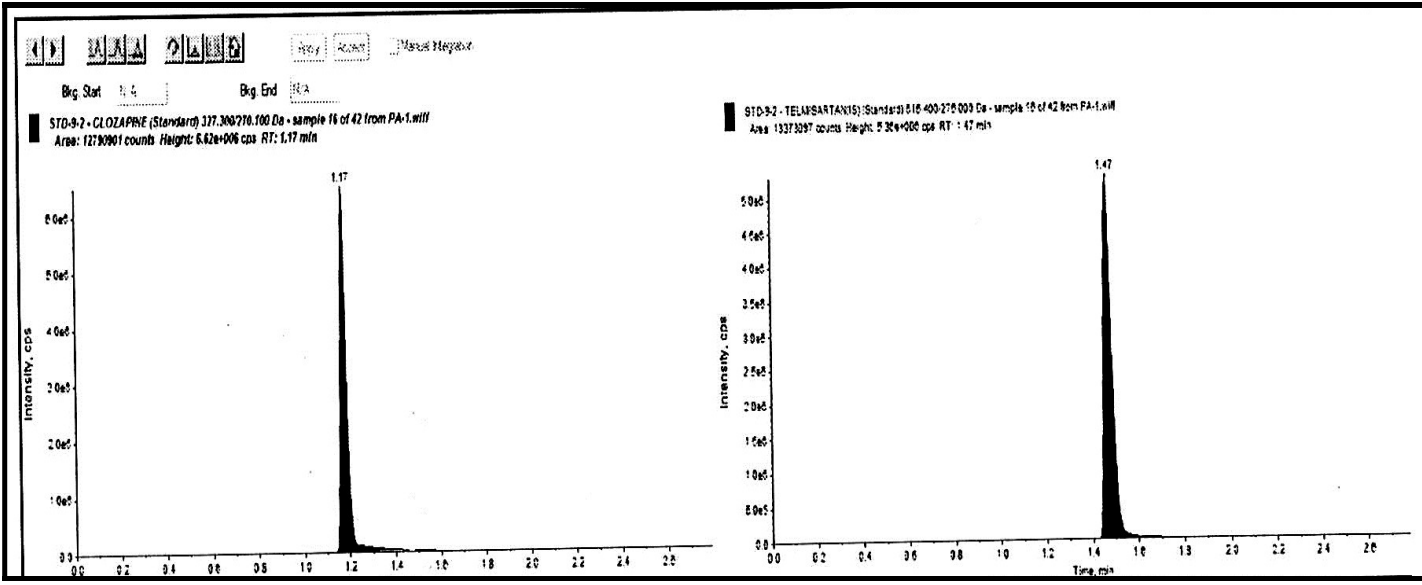

Fig.-6: Representative Example of ULOQ Chromatogram of Clozapine

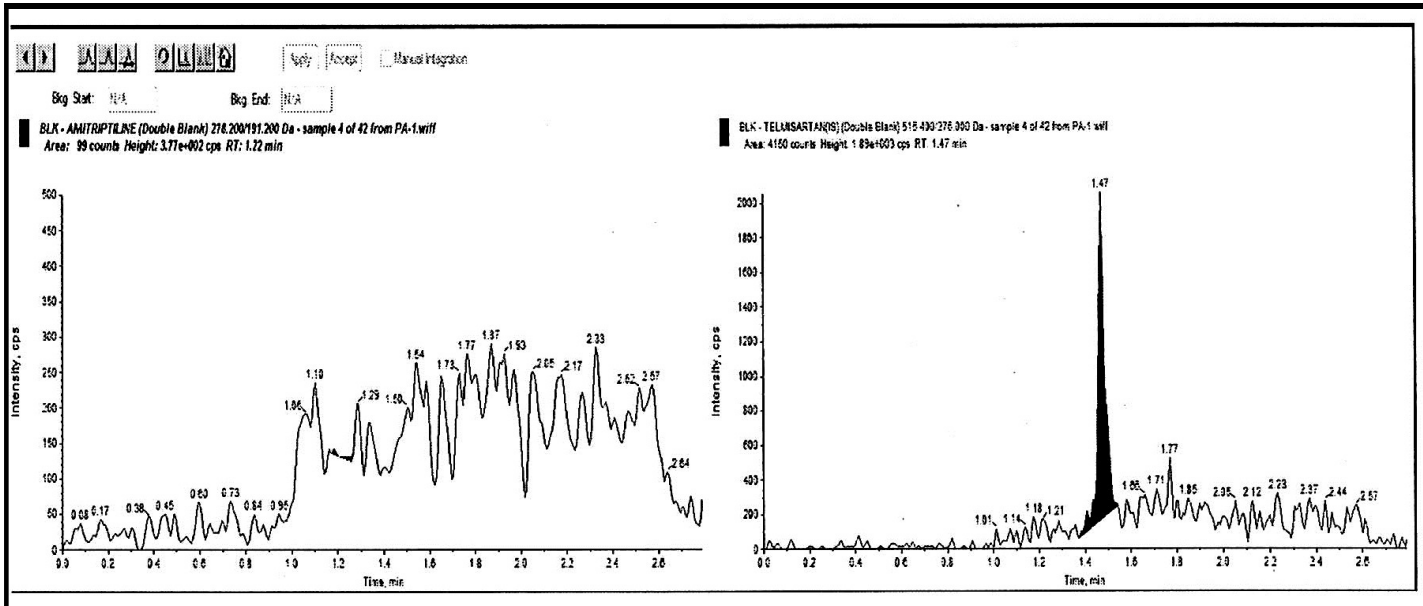

Fig.-7: Representative Example of Blank Chromatogram of Amitriptyline 
RASĀYAN J. Chem.

Vol. 13 | No. 1 |24 - 37| January - March | 2020

Table-4: Intra and Inter Run Precision and Accuracy of Clozapine and Amitriptyline in Human Plasma

\begin{tabular}{|c|c|c|c|c|c|c|c|}
\hline & & \multicolumn{6}{|c|}{ Concentrations(ng/ml) } \\
\hline & & \multicolumn{3}{|c|}{ Clozapine } & \multicolumn{3}{|c|}{ Amitriptyline } \\
\hline & & LQC(4.0) & MQC(500) & HQC(800) & LQC(4.0) & MQC(500) & HQC(800) \\
\hline \multirow{4}{*}{$\begin{array}{c}\text { BATCH } \\
1(\mathrm{~N}=6)\end{array}$} & Intra-run mean & 4.2 & 54.5 & 826.5 & 4.5 & 533.2 & 819.1 \\
\hline & Intra-run SD & 0.1 & 18.2 & 16.5 & 0.2 & 14.4 & 25.2 \\
\hline & Intra-run $\% \mathrm{CV}$ & 3.3 & 3.3 & 2.0 & 5.3 & 2.7 & 3.1 \\
\hline & Intra-run \%accuracy & 105 & 109 & 103 & 112 & 106 & 102 \\
\hline \multirow{4}{*}{$\begin{array}{l}\text { BATCH } \\
2(\mathrm{~N}=6)\end{array}$} & Intra-run mean & 4.2 & 526.1 & 833.7 & 4.2 & 529.3 & 831.1 \\
\hline & Intra-run SD & 0.1 & 5.9 & 10.3 & 0.2 & 9.3 & 15.4 \\
\hline & Intra-run $\% \mathrm{CV}$ & 3.2 & 1.1 & 1.2 & 5.5 & 1.8 & 1.8 \\
\hline & Intra-run \%accuracy & 105 & 105 & 104 & 105 & 106 & 104 \\
\hline \multirow{4}{*}{$\begin{array}{l}\text { BATCH } \\
3(\mathrm{~N}=6)\end{array}$} & Intra-run mean & 4.3 & 524.2 & 820.8 & 4.2 & 528.1 & 831.1 \\
\hline & Intra-run SD & 0.2 & 4.8 & 9.0 & 0.3 & 11.2 & 12.6 \\
\hline & Intra-run $\% \mathrm{CV}$ & 4.4 & 0.9 & 1.1 & 7.6 & 2.1 & 1.5 \\
\hline & Intra-run \%accuracy & 107 & 105 & 102 & 105 & 105 & 104 \\
\hline \multirow{4}{*}{$\begin{array}{c}\text { INTER } \\
\text { BATCH } \\
(\mathrm{N}=18)\end{array}$} & Inter-run mean & 4.1 & 508 & 826.3 & 4.3 & 506.4 & 802.2 \\
\hline & Inter-run SD & 0.2 & 5.6 & 9.1 & 0.4 & 2.4 & 5.4 \\
\hline & Inter-run \%CV & 4.8 & 1.1 & 1.2 & 9.3 & 0.5 & 0.67 \\
\hline & Inter-run \%accuracy & 103 & 102 & 103 & 107 & 101 & 100.2 \\
\hline
\end{tabular}

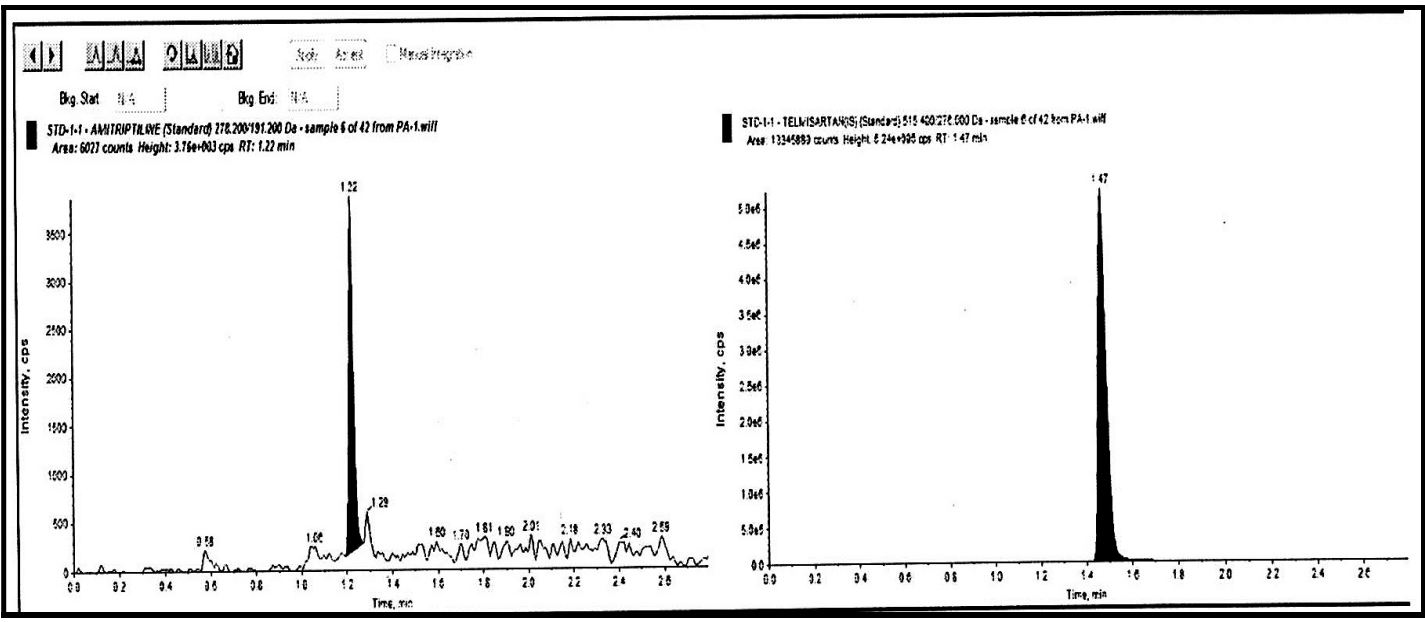

Fig.-8: Representative Example of LLOQ Chromatogram of Amitriptyline

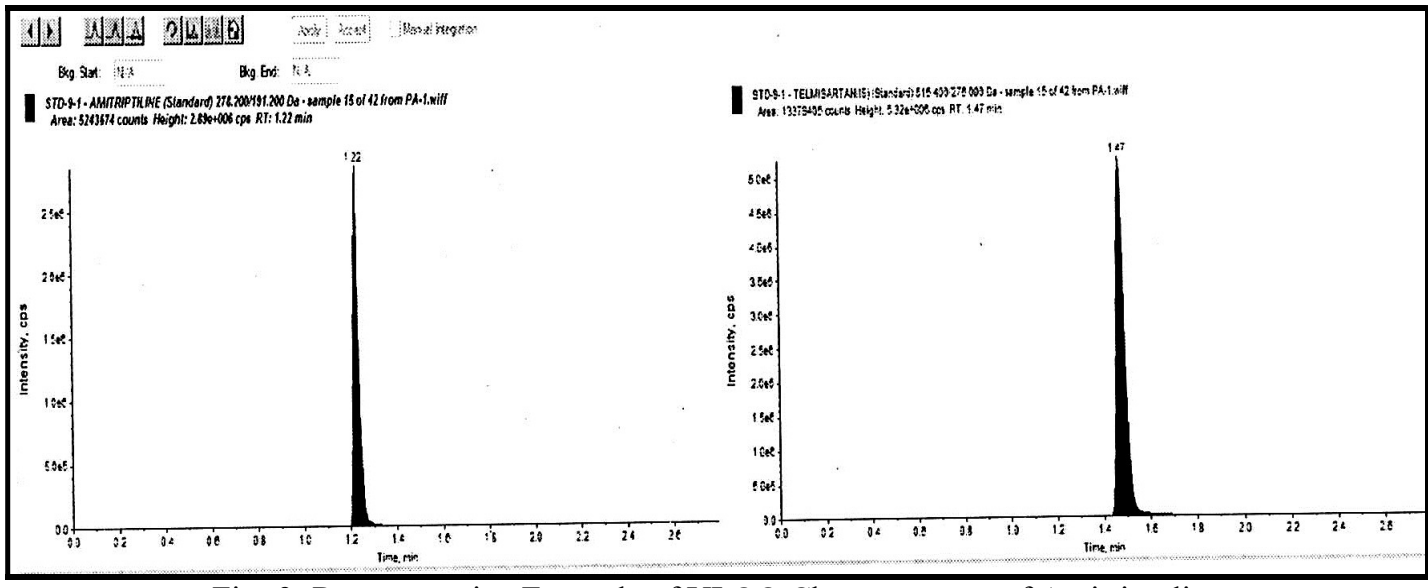

Fig.-9: Representative Example of ULOQ Chromatogram of Amitriptyline 
RASĀYAN J. Chem.

Vol. 13 | No. 1 |24 - 37| January - March | 2020

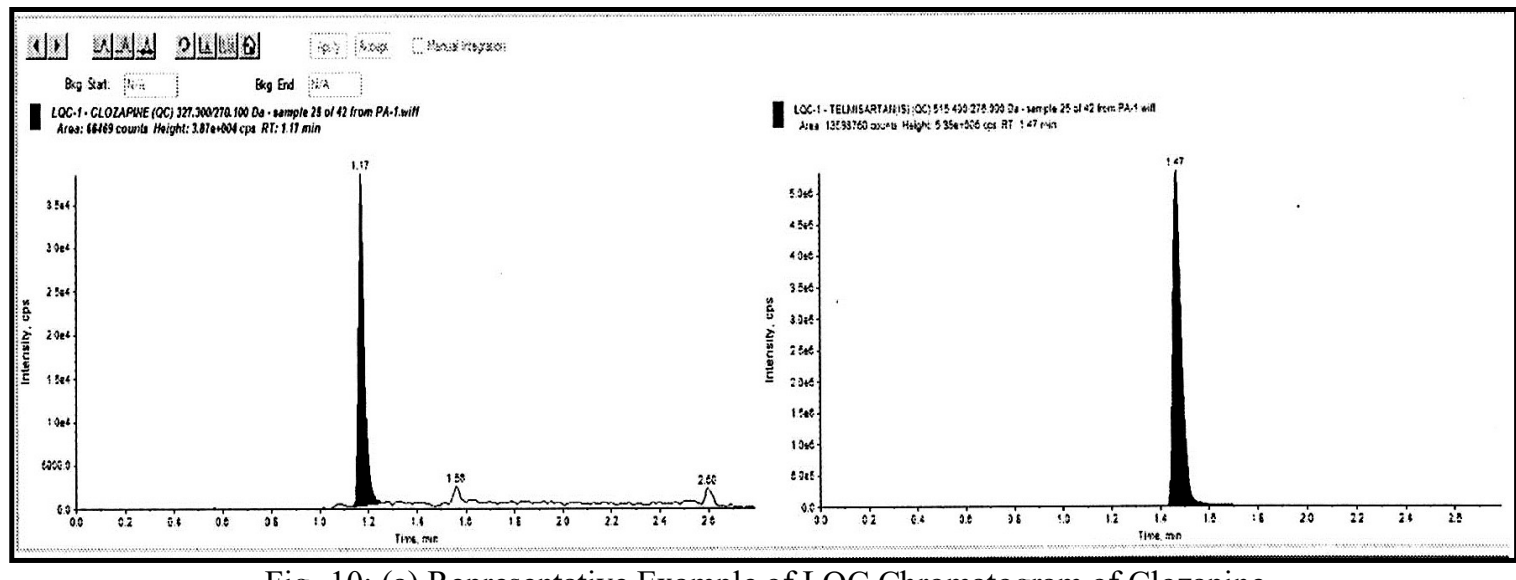

Fig.-10: (a) Representative Example of LQC Chromatogram of Clozapine

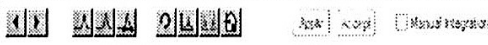

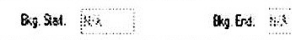

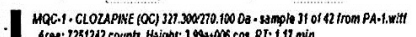

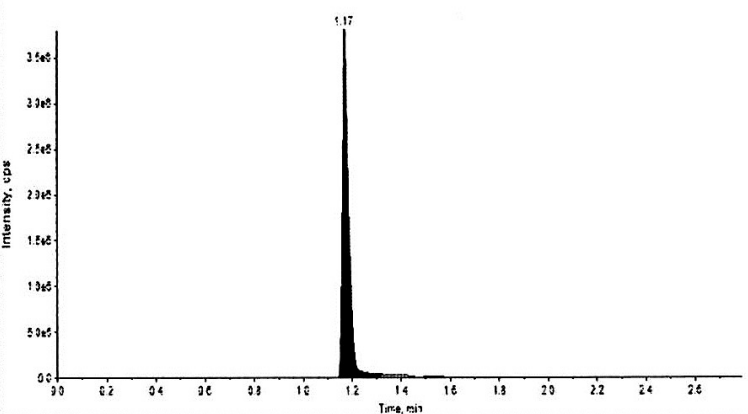

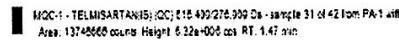

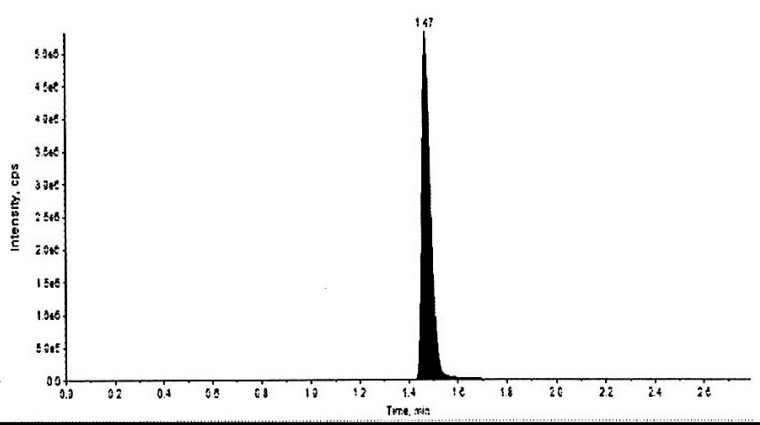

Fig.-10: (b) Representative Example of LQC Chromatogram of Clozapine Representative Example of MQC Chromatogram of Clozapine

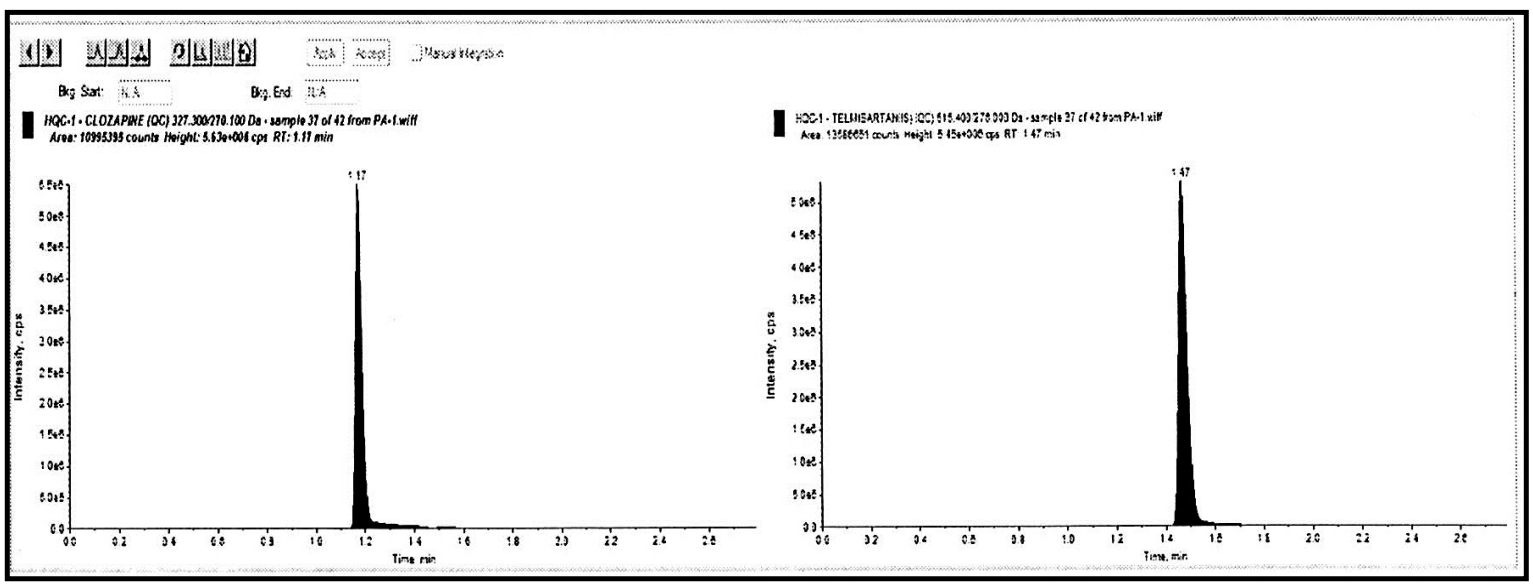

Fig.- 10:(c) Representative Example of HQC Chromatogram of Clozapine

Table-5: Showing Recovery Data of Clozapine and Amitriptyline

\begin{tabular}{c|c|c|c|c|c|c}
\hline \multirow{2}{*}{ Analyte } & \multicolumn{3}{|c|}{ Concentration } & AVG. & \multirow{2}{*}{ SD } & \multirow{2}{*}{$\% \mathrm{CV}$} \\
\cline { 2 - 4 } & LQC & MQC & HQC & RECOVERY & & \\
\hline Clozapine & 97.3 & 99.5 & 93.7 & 96.8 & 2.9 & 3.0 \\
\hline Amitriptyline & 96.4 & 98.3 & 97.6 & 97.4 & 0.96 & 0.98 \\
\hline
\end{tabular}


RASĀYAN J. Chem.

Vol. 13 | No. 1 |24 - 37| January - March | 2020

Recovery

From the LQC, MQC and HQC levels the recovery of analyte from K2EDTA plasma (Fig.- 10-11) was dictated by contrasting and their separate watery quality control tests (Table-5). The normal recovery for Clozapine and Amitriptyline was observed to be $73.47 \%$ and $99.85 \%(n=6)$ individually.

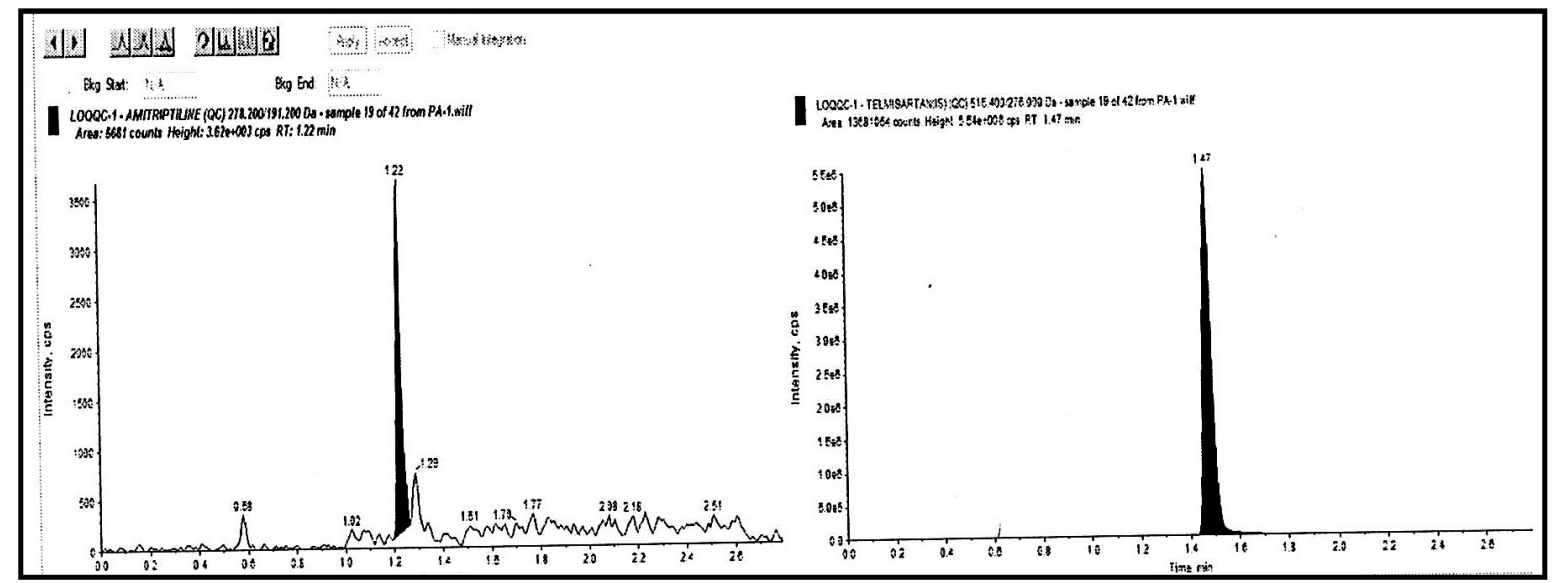

Fig.-11:(a) Representative Example of LQC Chromatogram of Amitriptyline

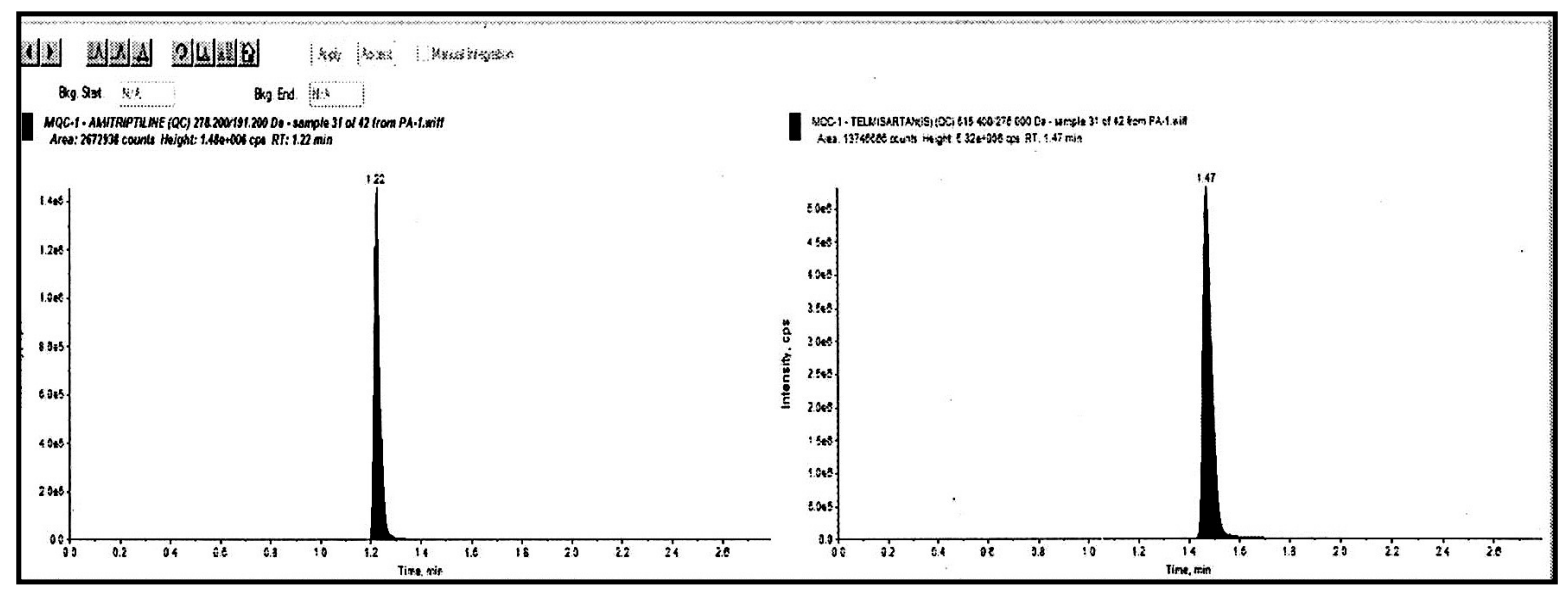

Fig.- 1:(b) Representative Example of MQC Chromatogram of Amitriptyline

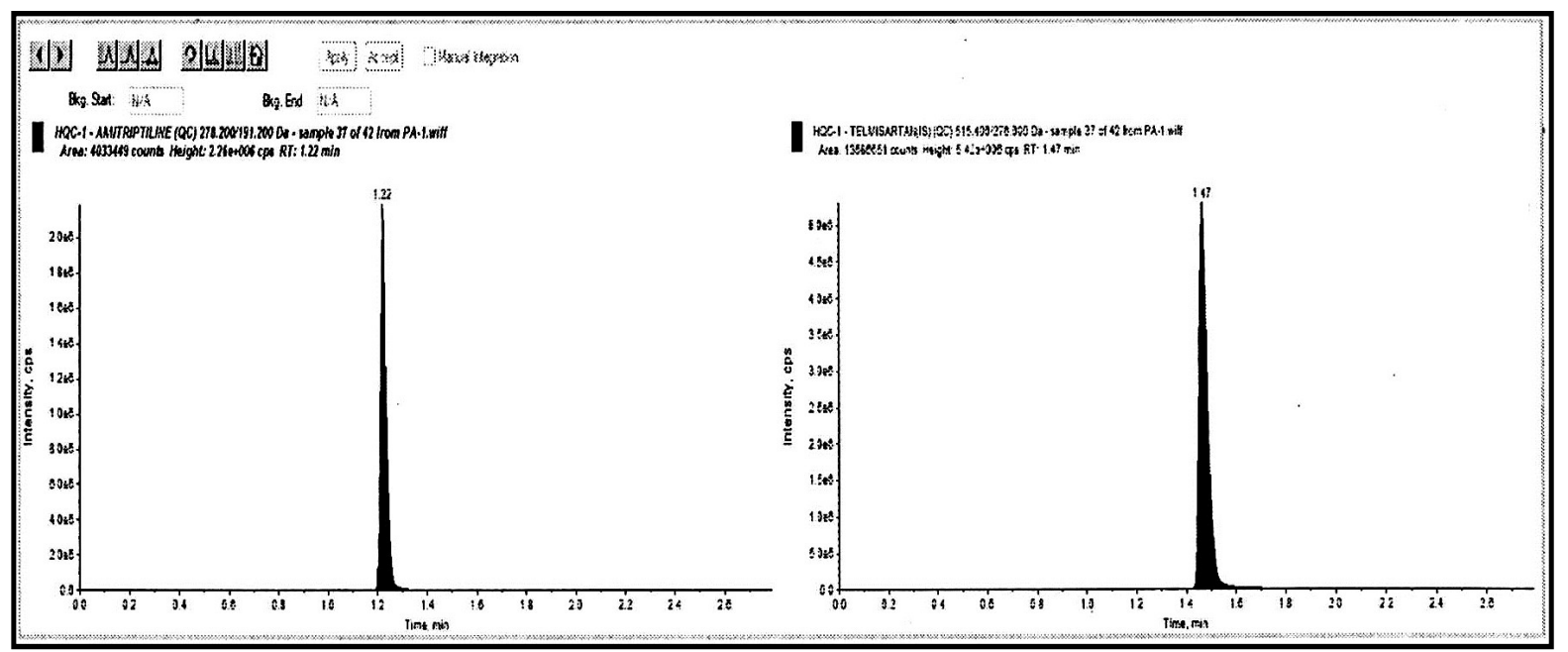

Fig.-11: (c) Representative Example of HQC Chromatogram of Amitriptyline 
RASĀYAN J. Chem.

Vol. 13 | No. 1 |24 - 37| January - March | 2020

Freeze-thaw Stability

For three cycles of freezing and thawing the quality control tests were done for low, mid and abnormal states to prove Freeze-thaw stability. Inter-day QC samples (Table-6) were used to determine the values of freeze-thaw stability ranges inside the precision and accuracy promoting the conclusion that the autosampler storage of the samples through three cycles demonstrates the no in-stability.

Table-6: Stability Data Showing the \%CV Analyte

\begin{tabular}{c|c|c|c|c}
\hline Analyte Name & Fresh Samples & $\begin{array}{c}\text { Freeze-thaw } \\
\text { Stability Samples }\end{array}$ & $\begin{array}{c}\text { Auto-sampler } \\
\text { Stability Samples }\end{array}$ & $\begin{array}{c}\text { Bench-top Stability } \\
\text { Samples }\end{array}$ \\
\hline \multicolumn{5}{|c}{ Clozapine } \\
\hline LQC & 7.2 & 9.6 & 9.6 & 8.7 \\
\hline MQC & 6.2 & 8.7 & 10.2 & 9.3 \\
\hline HQC & 5.1 & 6.5 & 8.2 & 9.1 \\
\hline LQC & 8.2 & Amitriptyline & 9.5 \\
\hline MQC & 6.9 & 10.2 & 11.4 & 11.4 \\
\hline HQC & 7.6 & 8.5 & 8.4 & \\
\hline
\end{tabular}

\section{Auto-sampler Stability}

Keep the samples for 24 hours under autosampler conditions $\left(40^{\circ} \mathrm{C}\right)$ and then differentiate it with fresh samples to determine the autosampler stability of K2EDTA in human plasma by performing quality control tests. Inter-day QC samples were used to determine the values of autosampler stability ( $\mathrm{n}=6$ at low, mid and high QC levels) ranges inside the precision and accuracy, promoting the conclusion that the auto-sampler storage of samples all through the run-time demonstrates the no in-stability.

\section{Bench-top Stability}

By keeping the samples for 4 hours at room temperature quality control tests were performed with K2EDTA human plasma to determine Bench-top stability and after that, they differentiate it with fresh samples. Inter-day QC samples were used to determine the values of bench-top stability ( $\mathrm{n}=6$ at low, mid and high QC levels) ranges inside the precision and accuracy, promoting the conclusion that the autosampler storage of samples all through the run-time demonstrates the no in-stability.

\section{CONCLUSION}

This method describes the simultaneous detection and accurate results of Clozapine and Amitriptyline in human plasma as per the regulatory guidelines and internal standard by using plain, rapid, perceptive LCMS/MS and Telmisartan. To extract the analyte and IS form human plasma precipitation method was used. By using gradient flow on the C18 column the chromatographic resolution of Clozapine and Amitriptyline was determined. The total chromatographic runtime was 3 min. The concentration range of $1-1000 \mathrm{ng} / \mathrm{mL}$ is used to obtain the linear response function of Clozapine and Amitriptyline. As per the regulatory guidelines the intra-day and inter-day accuracy and precision values of Clozapine and Amitriptyline were maintained.

\section{REFERENCES}

1. D.D. Berardis, G. Rapini, L. Olivieri, D.D. Nicola, C. Tomasetti, A. Valchera, M. Fornaro, F.D. Fabio, G. Perna, M.D. Nicola, G. Serafini, A. Carano, M. Pompili, F. Vellante, L. Orsolini, G. Martinotti, M.D. Giannantonio Ther. Adv. Drug Saf., 9, 5(2018), DOI: 10.1177/2042098618756261.

2. V. Milazzo, C.S.S. Servo, V. Crudo, C. Fulcheri, S. Maule, G. Vegllo. J. Hypertens., 1, 2 (2012), DOI: $10.4172 / 2167-1095.1000104$.

3. F. Amin, B.Bano. J Mol Genet Med., 08, 2 (2014), DOI: 10.4172/7147-0862.1000103.

4. P. Christensen, H.Y. Thomsen, O.L. Pedersen, P. Thayssen H. Oxhøj, P. Kragh-Sørensen, L.F. Gram Psychopharmacology. 87,2 (1985), DOI: 10.1007/BF00431810.

5. Y.-H. Ho, W.-K.Ko, H.-S. Kou, H.-L. Wu, S.-M. Wu. J. Chromatogr. B., 809, 1(2004), DOI: 10.1016/j.jchromb.2004.06.011 
RASĀYAN J. Chem.

Vol. 13 | No. 1 |24 - 37| January - March | 2020

6. M. A. Raggi, F. Bugamelli, R. Mandrioli, C. Sabbioni, V. Volterra, S. Fanali. J. Chromatogr. A., 916, 1-2 (2001), DOI:10.1016/S0021- 9673(01)00520-9

7. D. Zhou, F. Li., J. Pharm. Biomed., 35, 4(2004), DOI:10.1016/j.jpba.2004.02.019

8. A. Musenga, M.A. Saracino, D. Spinelli, E. Rozzato, G. Boncompagni, E. Kenndler, M,A. Raggi Anal. Chim. Acta., 612, 2(2008), DOI:10.1016/j.aca.2008.02.046

9. L. Mercolini, F. Bugamelli, E. Kenndler, G. Boncompagni, L. Franchini, M.A. Raggi. J. Chromatogr. B., 846, 1(2007), DOI:10.1016/j.jchromb.2006.09.019

10. M.-C. Chung, S.-K. Lin, W.-H. Chang, Michael W. Jann. J. Chromatogr., B, Biomed. Sci. Appl., 613, 1(1993), DOI: 10.1016/0378-4347(93)80212-M

11. R. Mandrioli, S. Fanali, A. Ferranti, M.A. Raggi, J. Pharm. Biomed., 30, 4(2002), DOI: $10.1016 / \mathrm{S} 0731-7085(02) 00395-3$

12. Z. Zhou, X. Li, K. Li, Z.Xie, Z. Cheng, W. Peng, F. Wang, R. Zhu, H. Li. J. Chromatogr. B., 802, 2 (2004), DOI:10.1016/j.jchromb.2003.11.037

13. E. Choong, S. Rudaz, A. Kottelat, D. Guillarme, J.-L. Veuthey, C.B. Eap, J. Pharm. Biomed., 50, 5 (2009), DOI:10.1016/j.jpba.2009.07.007

14. A. Avenosoa, G. Facciolaa, G. M.Compoa, A. Faziob, E. Spinaa. J. Chromatogr., B, Biomed. Sci. Appl., 714, 2(1998), DOI: 10.1016/S0378-4347(98)00202-3

15. I. Vardakou, A. Dona, C. Pistos, G. Alevisopoulos, S. Athanaselis, C. Maravelias, C. Spiliopoulou. J. Chromatogr. B., 878, 25 (2010), DOI:10.1016/j.jchromb.2010.07.001

16. C.B. Eap, G. Bouchoux, M. Amey, N. Cochard, L. Savary, P. Baumann. J. Chromatogr. Sci., 36, 7 (1998), DOI: $10.1093 / \mathrm{chromsci} / 36.7 .365$.

17. M. Roman, R. Kronstrand, D. Lindstedt, M. Josefsson. J. Anal. Toxicol., 32, 2(2008). DOI: $10.1093 / \mathrm{jat} / 32.2 .147$

18. M. Aravagiri, S.R. Marder, J. Pharm. Biomed., 26, 2(2001), DOI: 10.1016/S0731-7085(01)00410-1.

19. A. Wohlfarh, N. Toepfner, M. H.-Clausen, V. Auwarter. Anal. Bioanal. Chem., 400, 3 (2011), DOI: 10.1007/s00216-011-4831-8

20. S.-M. Wu, H.-L. Wu, W.-K.Ko, S.-H. Chen. Anal. Chim. Acta., 413, 1(2000), DOI:10.1016/S00032670(00)00814-X

21. C.-C. Chen, S.-M. Wu, Y.-H. Huang, Wei-Kung, H,-S, Kou, H,-L, Wu. Anal. Chim. Acta., 517,1(2004), DOI: $10.1016 /$ j.aca.2004.05.002

22. M. D. Cantu, S. Hillebrand, M. Eugenia C. Queiroz, F.M. Lancas, E. Carrilho. J. Chromatogr. B., 799, 1(2004), DOI: $10.1016 /$ j.jchromb.2003.10.037

23. A. Asghari, Z. Saffarzadeh, M. Bazregar, M. Rajabi, L. Boutorabi, Microchem. J., 130 (2017), DOI: 10.1016/j.microc.2016.08.014

24. R. Ishida, T. Ozaki, H. Uchida, T. Irikura. J. chromatogr., B, Biomed. Sci. Appl., 305 (1984), DOI: $10.1016 / \mathrm{S} 0378-4347(00) 83315-0$

25. P. Ghahramani, M.S. Lennard. J. Chromatogr., B, Biomed. Sci. Appl., 685, 2(1996), DOI: $10.1016 / \mathrm{S} 0378-4347(96) 00193-4$

26. S. Hartter, C. Hiemke. J. Chromatogr., B, Biomed. Sci. Appl., 578, 2(1992), DOI: 10.1016/03784347(92)80426-Q.

27. E. Subhashini, B. Syama Sundhar, Rasayan J. Chem., 7(1), 55(2014).

28. S.S.N. Venkata, B. Haribabu, Rasayan J. Chem., 8(4), 433(2015).

29. E.J.J. Berm, J. ,Paardekooper, E. Brummel-Mulder, E. Hak, B. Wilffert, J.G. Maring. Talanta. 134, 1 (2015), DOI:10.1016/j.talanta.2014.10.041

30. Y. Shen, P. Xu, J. Pharm. Biomed., 53, 3(2010), DOI:10.1016/j.jpba.2010.04.031

31. T. Shinzouka, M. Terada, E. Tanaka. Forensic Sci. Int., 162, 1(2006), DOI: $10.1016 /$ j.forsciint.2006.03.038.

32. P. Rajagopaludu, N. Saritha, N. Devanna, D. Jayasimha Rayalu, Rasayan J. Chem., 12(2), 402, (2019), DOI:

[RJC-5466/2019] 